\title{
Mathematical modelling of solid desiccant systems
}

\author{
Anna Pacak $^{1, *}$, Demis Pandelidis ${ }^{1}$, and Sergey Anisimov ${ }^{1}$ \\ ${ }^{1}$ Wrocław University of Science and Technology, Faculty of Environmental Engineering, Department of Air Conditioning, \\ Heating, Gas Engineering and Air Protection, 4/6 Norwida st., 50-373 Wroclaw, Poland
}

\begin{abstract}
In this study, the mathematical model equations for solid desiccant system integrated with indirect evaporative coolers with Maisotsenko - Cycle are presented. The authors chose the modified $\varepsilon-$ NTU method to describe heat and mass transfer processes in regenerative indirect evaporative cooler and desiccant wheel. The models based on the $\varepsilon-\mathrm{NTU}$ method show satisfactory agreement with experimental results. That is why this method allows to analyze and develop the performance of solid desiccant systems. In this study, the models allowed to prove that solid desiccant system with an additional heat exchanger before the desiccant wheel (System 1) obtains higher thermal COP values, higher humidity ratio drop and lower supply airflow temperatures in comparison to system with only one heat exchanger after the desiccant wheel (System 2).
\end{abstract}

\section{Introduction}

International Energy Agency (IEA) reported that the space cooling at homes and offices is in the fastest growing demand among end-use in buildings. What is more, it has been increasing by $3.3 \%$ each year since 2010 and the trend shall continue for the next three decades. In 2017 cooling constituted $20 \%$ of electricity usage in the building sector and due to this fact IEA stresses the urgent need for policy action to improve cooling efficiency [1]. It is the reason why the alternative air conditioning (AC) systems have to be investigated, in order to reduce the exploitation costs of space cooling [2]. Indirect evaporative cooling (IEC) is considered as the most promising solution which is able to limit the power demand in typical AC systems by implementing heat and mass exchanger which uses water to cool the airflow [3]. In order to correctly apply IEC units in the air conditioning systems, they have to be detail studied from the theoretical standpoint. It is worth to mention that the experimental measurements provide accurate results. Nevertheless, the cost of experiments is relatively high. The mathematical modelling is an alternative approach which may help to collect data for specific input conditions. It is the fact that developed models must be validated on the base of an experimental data. After the validation models allow to obtain the missing data which is difficult to collected [4]. Mathematical modeling of those devices enables the analysis of their performance in different system arrangements [5, 6]. Moreover, it allows to determine whether it is worth to apply this indirect evaporative cooler in specific climate conditions. Indirect evaporative coolers does not provide the humidity ratio drop. That is why for moderate climate should be supported by desiccant wheel in which the air is dehumidified.

There are three main methods used for mathematical modeling of heat and mass transfer processes:

- Models based on the Reynolds equations;

- Models based on the boundary layer equations;

Models based on the $\varepsilon-\mathrm{NTU}$ method.

Mathematical models based on the Reynolds and boundary layer equations allow obtaining detailed information about thermal parameters in every portion of the studied object. However, these models are often very hard to solve in modern indirect evaporative units, because they are often characterized by complicated air flow and water distribution [7, 8]. The complicated structure of the models often requires many simplifications about exchangers' geometry and air flow characteristics, which may lead to inaccurate results $[7,8]$. That is why authors give preference to models based on modified $\varepsilon-\mathrm{NTU}$ method. These models assume that air flow is treated as a gaseous fluid with constant temperature, velocity and mass transfer potential which are equal to bulk average values in sections normal to the exchangers' plate [7, 8]. In this paper the potential of applying $\varepsilon-\mathrm{NTU}$ models for description of IEC units and also the desiccant wheel is presented using a novel desiccant cooling system with an additional heat exchanger before the desiccant wheel as the example.

\section{System description}

The analyzed system (Fig. 1 (a)) includes a combination of two regenerative Maisotsenko-Cycle (M-Cycle) indirect evaporative air coolers combined with a desiccant wheel: first M-Cycle unit is located

Corresponding author: anna.pacak@pwr.edu.pl 
before the desiccant wheel, to initially pre-cool the outdoor air, before it enters the dehumidification section. This arrangement allows for two benefits: it increases the dehumidification level and it allows to achieve lower temperatures at the outlet of the desiccant wheel. These two factors allow the second stage exchanger to operate more effectively and therefore reach lower supply air temperatures. It should be mentioned that adding an extra exchanger to the system does not significantly increase its costs (M-Cycle air coolers are usually made out of plastic [9]), also with the appropriate sizing of the $1^{\text {st }}$ stage exchanger it should not significantly affect the pressure drop. Proposed system will be compared with the traditional solution, based on the desiccant wheel and a regenerative unit (Fig. 1(b)). Proposed, novel solution in this paper will be marked as System 1 (new system) and System 2 (traditional system).

(a)

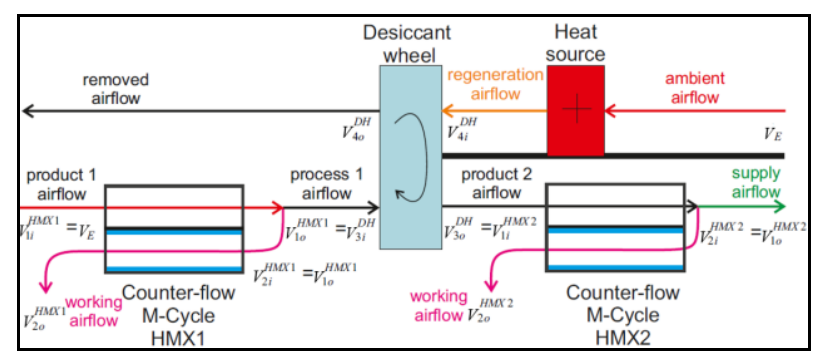

(b)

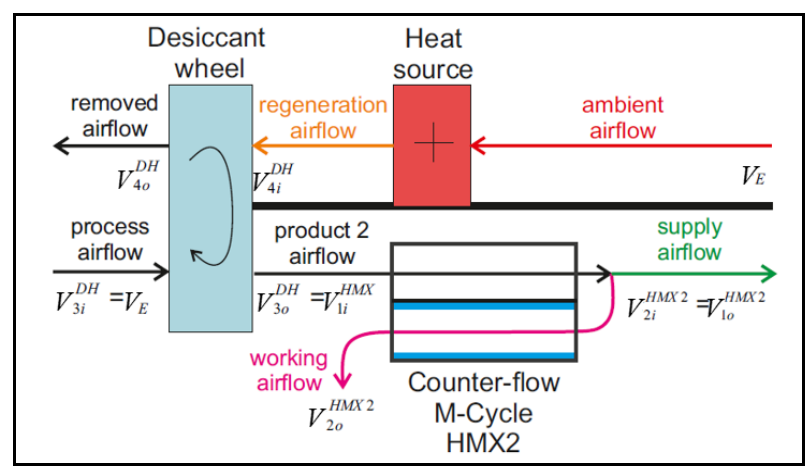

Fig. 1. Scheme of the systems analyzed in this study. (a) System 1 with an additional HMX1 before the desiccant wheel. (b) System 2 with only one HMX2 used.

\section{Methods}

\subsection{Mathematical model equations}

Both M-Cycle indirect evaporative air coolers and desiccant wheel are simulated using an original $\varepsilon-\mathrm{NTU}$ heat and mass transfer model $[10,11]$. In this paper only the final forms of the mathematical models equations for M-Cycle heat exchanger and desiccant wheel are presented.

\subsubsection{Regenerative heat exchanger}

The mathematical model is based on energy balance (eq. 1) for the primary airflow and energy and mass balance for working airflow (eq. 2 and eq. 3 respectively). It means that in dry channel only the temperature decrement is observed and in wet channel the temperature and humidity ratio changes in regenerative heat and mass exchanger (Fig. 2).

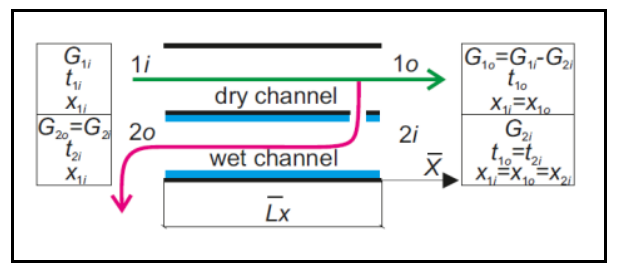

Fig. 2. Schematic of the regenerative M-Cycle heat exchanger.

The main idea of the M-Cycle process is indirect precooling of the working airflow before it enters the wet channels (Fig. 2) [12]. Like in the case of typical IEC, the primary airflow in the dry channels of the M-Cycle HMX decreases its temperature without increasing its moisture content. The basic assumptions for the mathematical model of the counter-flow M-Cycle HMX with the detail conversion of the heat transfer equations are presented below:

Assumptions:

- Heat exchange with the surroundings are negligible. Steady state operation conditions.

- Airflow physical properties are ideal and air is incompressible gas.

- Water rate consumption is used for evaporation and for keeping the plate surface at a saturated state.

- Air flow heat capacity is much larger than that of the water (i.e., W2 > Ww).

- Driving force of mass transfer is humidity ratio gradient (gradient of partial pressure of the water vapor).

- Kinetic properties of air stream and water is constant and assumed as equal to bulk average values.

(a)

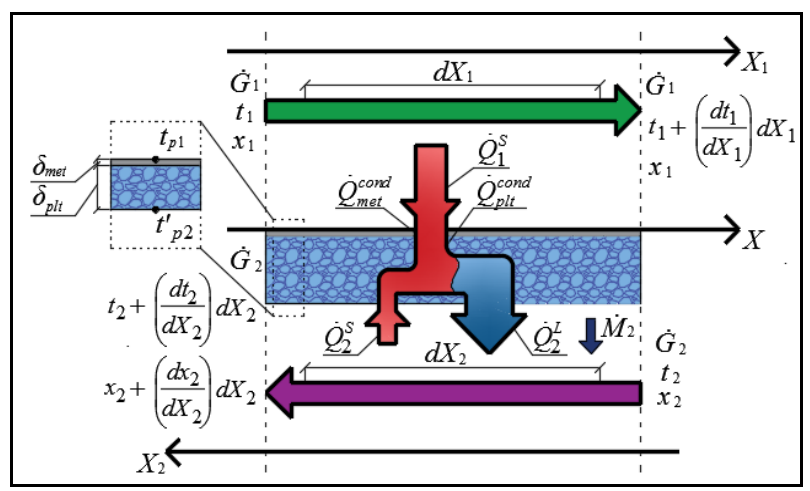


(b)

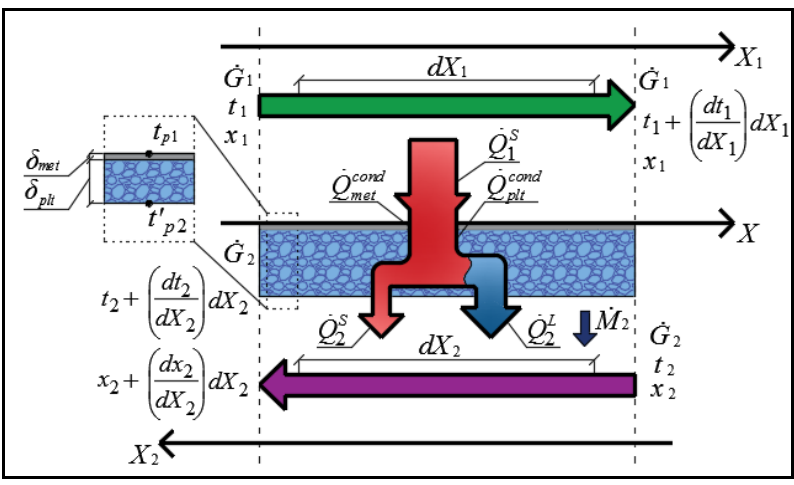

Fig. 3. Schematic of the heat and mass transfer mathematical model: (a) at the entrance part of wet channel. (b) at the exit part of wet channel.

The example schematics of heat and mass transfer in calculation control volumes in the dry and wet channels, which shows the operating mechanism of mathematical model is presented in Figs. 3 (a) and (b).

The following balance equations can be written for the air streams passing through control volume in the product part of the HMX (Fig. 3 (a) and (b)). The basic energy balance equations transformations are presented in [13].

- For the air stream in the dry channel

The energy balance:

$$
\frac{d t_{1}}{d \bar{X}}=\mathrm{NTU}_{1}\left(t_{p 1}-t_{1}\right)
$$

- $\quad$ For the air stream in the wet channel

The energy balance:

$$
\frac{d t_{2}}{d \bar{X}}=-\mathrm{NTU}_{2}\left(t_{p 2}^{\prime}-t_{2}\right)\left[1+\left(\frac{\sigma_{p}}{\mathrm{Le}}\right)_{2}\left(\frac{c_{g}}{c_{p}}\right)_{2}\left(x_{p 2}^{\prime}-x_{2}\right)\right]
$$

The mass balance for the water vapor inside the wet channel:

$$
\frac{d x_{2}}{d \bar{X}}=-\mathrm{NTU}_{2}\left(\frac{\sigma_{p}}{\mathrm{Le}}\right)_{2}\left(x_{p 2}^{\prime}-x_{2}\right)
$$

The overall balance relationship (eq. (4)) for the whole filling structure obtained by simultaneous rearranging of basic energy balance equations.

$$
\left(\frac{d t_{1}}{d \bar{X}}\right)-\left(\frac{C_{2}}{C_{1}}\right)\left[\left(\frac{d t_{2}}{d \bar{X}}\right)+\frac{\left(i_{g 2}-i_{p 2}^{\prime}\right)}{c_{p 2}}\left(\frac{d x_{2}}{d \bar{X}}\right)\right]=0
$$

The mathematical model is supplemented with the initial conditions, establishing the parameters at the entrance to the appropriate channels.

\section{For regenerative heat exchanger HMX1}

For primary air at inlet to the dry channel:

$$
\begin{gathered}
t_{1 i}^{H M X 1} \mid \begin{array}{l}
=t_{E} \\
\bar{X}=0.0 \\
\bar{Y}=(0.0 \ldots 1.0)
\end{array} \\
x_{1 i}^{H M X 1} \mid \begin{array}{l}
=x_{E} \\
\bar{X}=0.0 \quad x_{1}^{H M X 1} \\
\bar{Y}=(0.0 \ldots 1.0)
\end{array} ; \quad \begin{array}{l}
=x_{1 i}^{H M X 1}=\text { const } \\
\bar{X}=(0.0 \ldots 1.0) \\
\bar{Y}=(0.0 \ldots 1.0)
\end{array}
\end{gathered}
$$

For the working air at inlet to the wet channel:

$$
t_{2 i}^{H M X 1}\left|\begin{array}{ll}
=t_{1 o}^{H M X 1} & x_{2 i}^{H M X 1} \\
\bar{X}=1.0 & ;
\end{array}\right| \begin{aligned}
& =x_{1 o}^{H M X 1}=x_{E} \\
& \bar{X}=(0.0 \ldots 1.0)
\end{aligned} ;
$$

For regenerative heat exchanger HMX2

For primary air at inlet to the dry channel:

$$
\begin{aligned}
& t_{1 i}^{H M X 2} \mid \begin{array}{l}
=t_{3 o}^{D H} \\
\bar{X}=0.0 \\
\bar{Y}=(0.0 \ldots 1.0)
\end{array} \\
& \left.x_{1 i}^{H M X 2} \mid \begin{array}{l}
=x_{3 o}^{D H} \\
\bar{X}=0.0 \quad ; \\
\bar{Y}=(0.0 \ldots 1.0)
\end{array} \quad ; \quad \begin{array}{l}
x_{1}^{H M X 2} \\
\bar{X}=(0.0 \ldots 1.0) \\
\bar{Y}=(0.0 \ldots 1.0)
\end{array}\right)
\end{aligned}
$$

For the working air at inlet to the wet channel:

$$
t_{2 i}^{H M X 2}\left|\begin{array}{ll}
=t_{1 o}^{H M X 2} & x_{2 i}^{H M X 2} \\
\bar{X}=1.0 & ;
\end{array}\right| \begin{aligned}
& =x_{1 o}^{H M X 2}=x_{3 o}^{D H} \\
& \bar{Y}=(0.0 \ldots 1.0)
\end{aligned} \mid \begin{aligned}
& \bar{X}=(0.0 \ldots 1.0)
\end{aligned}
$$

\subsubsection{Desiccant wheel}

The governing equations for the model of the rotary dehumidifier are presented in this section the assumptions for mathematical model creation are published in [11].

General assumptions:

- here is a convective heat and mass transfer between the air and the desiccant material

- the model is one-dimensional

- heat of sorption during the adsorption process is totally released to the desiccant core

- heat of adsorption and heat of desorption are equal

- $\quad$ airflow is treated as an ideal incompressible gas mixture of dry air and the water vapor

- the airflow through the desiccant wheel is laminar

- heat losses to the surroundings are negligible

- constant angular velocity 
- the channels dimensions of the desiccant wheel have the same values through the whole desiccant core.

The scheme of the model of the desiccant wheel is presented in Fig 4. The heat and mass transfer balance equations for the process the regeneration airflow and for process and regeneration sector are summarized respectively. They describe the temperature and humidity ratio changes for process and regeneration airflow and for process and regeneration sector. It should be mentioned that the proposed model not only takes into consideration the latent heat of adsorption/desorption and sensible heat transfer between the air and desiccant, it also considers additional sensible heat transfer connected with the specific heat capacity of the adsorbed/desorbed moisture. Due to this fact, the energy balance equations developed for the airflow on the process air side and for desiccant matrix on the regeneration air side are presented in the form which represents the physical phenomenon that they are describing - in dehumidifying section the factor connected with specific heat capacity of the adsorbed moisture is included in the desiccant matrix energy balance, in regeneration section it is included in the energy balance for the airflow.

\section{For the process airflow}

The energy conservation balance:

$$
\frac{\partial t_{3}}{\partial \bar{Z}_{3}}=\mathrm{NTU}_{3}\left(t_{d 3}-t_{3}\right)
$$

Where: $\mathrm{NTU}_{3}=\left(\alpha_{3} F_{3}\right) /\left(G_{3} c_{p 3}\right)$

The mass conservation balance:

$$
\frac{\partial x_{3}}{\partial \bar{Z}_{3}}=\mathrm{NTU}_{3} \frac{1}{\operatorname{Le}_{3}}\left(x_{d 3}-x_{3}\right)
$$

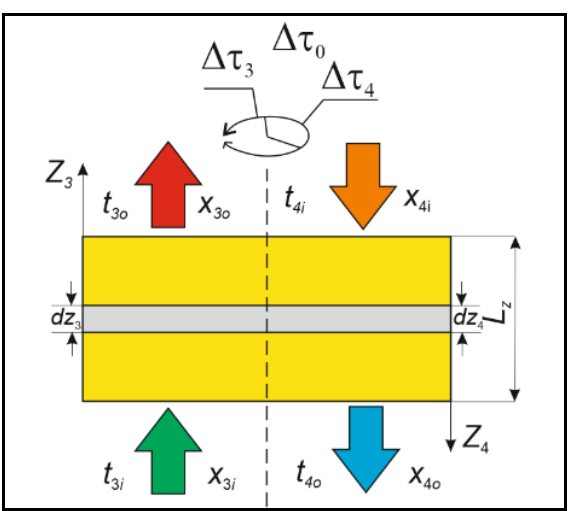

Fig. 4. Schematic of the heat and mass transfer mathematical model of the desiccant wheel.
For the regeneration airflow

The energy conservation balance:

$$
\frac{\partial t_{4}}{\partial \bar{Z}_{4}}=\mathrm{NTU}_{4}\left(t_{d 4}-t_{4}\right)\left[1+\left(\frac{c_{g}}{c_{p} \mathrm{Le}}\right)_{4}\left(x_{d 4}-x_{4}\right)\right]
$$

The mass conservation balance:

$$
\frac{\partial x_{4}}{\partial \bar{Z}_{4}}=\mathrm{NTU}_{4} \frac{1}{\mathrm{Le}_{4}}\left(x_{d 4}-x_{4}\right)
$$

Where: $\mathrm{NTU}_{4}=\left(\alpha_{4} F_{4}\right) /\left(G_{4} c_{p 4}\right)$

For the desiccant matrix of process sector:

The energy conservation balance:

$$
\frac{\partial t_{d 3}}{\partial \bar{\tau}}=\mathrm{NTU}_{d 3}^{*}\left(t_{3}-t_{d 3}\right)+\frac{\partial W_{d 3}}{\partial \bar{\tau}}\left[\frac{q_{3}^{\text {sorp }}+c_{g 3}\left(t_{3}-t_{d 3}\right)}{c_{d 3}}\right]
$$

The mass conservation balance:

$$
\frac{\partial W_{d 3}}{\partial \bar{\tau}}=\mathrm{NTU}_{d 3}^{*}\left(\frac{c_{d}}{c_{p} \operatorname{Le}}\right)_{3}\left(x_{3}-x_{d 3}\right)
$$

Where: $\mathrm{NTU}_{d 3}^{*}=\left(\alpha_{3} F_{d 3} \Delta \tau_{0}\right) /\left(M_{d 3} c_{d 3}\right)$

For the desiccant matrix of regeneration sector:

The energy conservation balance:

$$
\frac{\partial t_{d 4}}{\partial \bar{\tau}}=\mathrm{NTU}_{d 4}^{*}\left(t_{4}-t_{d 4}\right)+\frac{\partial W_{d 4}}{\partial \bar{\tau}}\left(\frac{q_{4}^{\text {sorp }}}{c_{d 4}}\right)
$$

The mass conservation balance:

$$
\frac{\partial W_{d 4}}{\partial \bar{\tau}}=\mathrm{NTU}_{d 4}^{*}\left(\frac{c_{d}}{c_{p} \operatorname{Le}}\right)_{4}\left(x_{4}-x_{d 4}\right)
$$

Where: $\mathrm{NTU}_{d 4}^{*}=\left(\alpha_{4} F_{d 4} \Delta \tau_{o}\right) /\left(M_{d 4} c_{d 4}\right)$

The mathematical model is supplemented with initial, switching and boundary conditions:

Initial conditions:

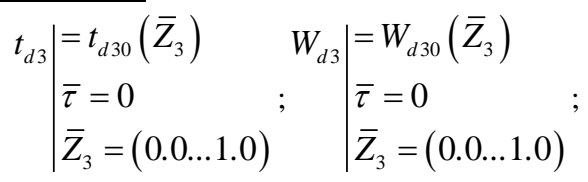

Boundary conditions:

Absorption side:

$$
t_{3} \mid \begin{aligned}
& =t_{3 i}^{D W} \\
& \bar{Z}_{3}=0 \\
& \bar{\tau}=\left((j-1) \ldots\left(\Delta \bar{\tau}_{3}+(j-1)\right)\right)
\end{aligned}
$$




$$
x_{3} \mid \begin{aligned}
& =x_{3 i}^{D W} \\
& \bar{Z}_{3}=0 \\
& \bar{\tau}=\left((j-1) \ldots\left(\Delta \bar{\tau}_{3}+(j-1)\right)\right)
\end{aligned}
$$

Desorption side:

$$
\begin{aligned}
& t_{4} \mid \begin{array}{l}
=t_{4 i}^{D W} \\
\bar{Z}_{4}=0 \\
\bar{\tau}=\left(\left(\Delta \bar{\tau}_{3}+(j-1)\right) \cdots j\right)
\end{array} \\
& x_{4} \mid \begin{array}{l}
=x_{4 i}^{D W} \\
\bar{Z}_{4}=0 \\
\bar{\tau}=\left(\left(\Delta \bar{\tau}_{3}+(j-1)\right) \ldots j\right)
\end{array}
\end{aligned}
$$

Switching conditions:

$$
\begin{aligned}
& t_{d 4}\left(Z_{4}\right) \mid \begin{array}{ll}
=t_{d 3}\left(\bar{Z}_{3}\right) & W_{d 4}\left(Z_{4}\right) \\
\bar{Z}_{3}=(0.0 \ldots 1.0) & =W_{d 3}\left(\bar{Z}_{3}\right) \\
\bar{Z}_{4}=1-\bar{Z}_{3} & ; \\
\bar{\tau}=\Delta \bar{\tau}_{3}+(j-1) & \bar{Z}_{3}=(0.0 \ldots 1.0) \\
\bar{Z}_{4}=1-\bar{Z}_{4} & \bar{\tau}=\Delta \bar{\tau}_{3}+(j-1)
\end{array} \\
& t_{d 3}\left(Z_{3}\right)\left|\begin{array}{l}
=t_{d 4}\left(\bar{Z}_{4}\right) \quad W_{d 3}\left(Z_{3}\right) \\
\bar{Z}_{4}=(0.0 \ldots 1.0) ; \\
\bar{Z}_{3}=1-\bar{Z}_{4} \\
\bar{\tau}=j
\end{array}\right| \begin{array}{l}
=W_{d 4}\left(\bar{Z}_{4}\right) \\
\bar{Z}_{4}=(0.0 \ldots 1.0) \\
\bar{Z}_{3}=1-\bar{Z}_{4} \\
\bar{\tau}=j
\end{array}
\end{aligned}
$$

Proposed models are implemented in a multi-module computer simulation program. A four-dimensional computational numerical code based on the modified Runge-Kutta method [14] which was implemented using the Wolfram Mathematica environment. Detailed validation is presented in $[10,11]$. General validation charts for regenerative heat exchanger and desiccant wheel are presented in next section.

\section{Validation}

\section{Counter- flow regenerative heat exchanger}

The $\varepsilon$-NTU model was verified experimentally using an data given by Riangvilaikul and Kumar [15]. The parameters measured included: the volumetric air flow rate and the dry and wet-bulb temperatures. To conduct the validation the model was set to the same operating conditions as for the experimental cases, including the exchanger geometry and inlet air-flow conditions. Obtained outlet airflow temperatures from the model and an experiment for selected arguments are presented in the validation in Fig. 5(a) and (b). For the first case Fig. 5(a) the differences in obtained supply air temperature, calculated from the equation were at most $4 \%$, the coefficient of determination $\mathrm{R} 2$ between experiment and model was established as equal 0.998. For the second case Fig. 5(b) discrepancies between the model and experiment are at most $2 \%$ and the R2 correlation is equal 0.999. It can be seen that the experimental and simulation results show satisfactory agreement, thus the model can be successfully used to predict performance of the regenerative HMX [9]. (a)

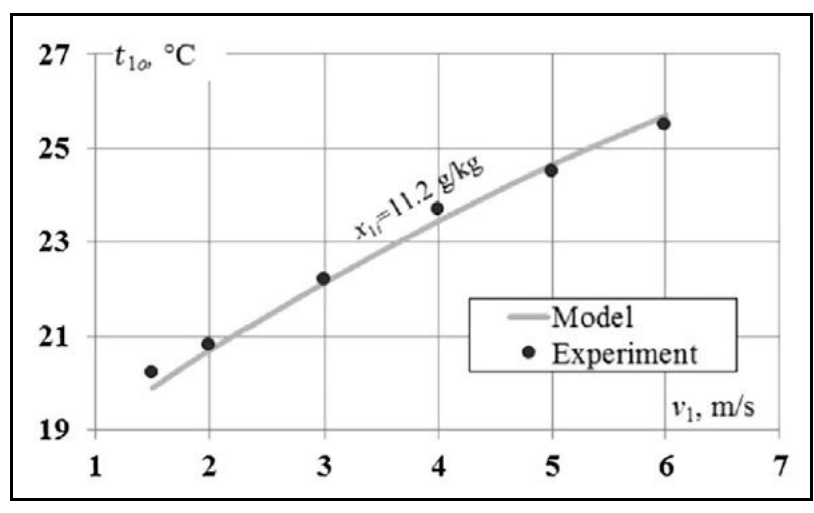

(b)

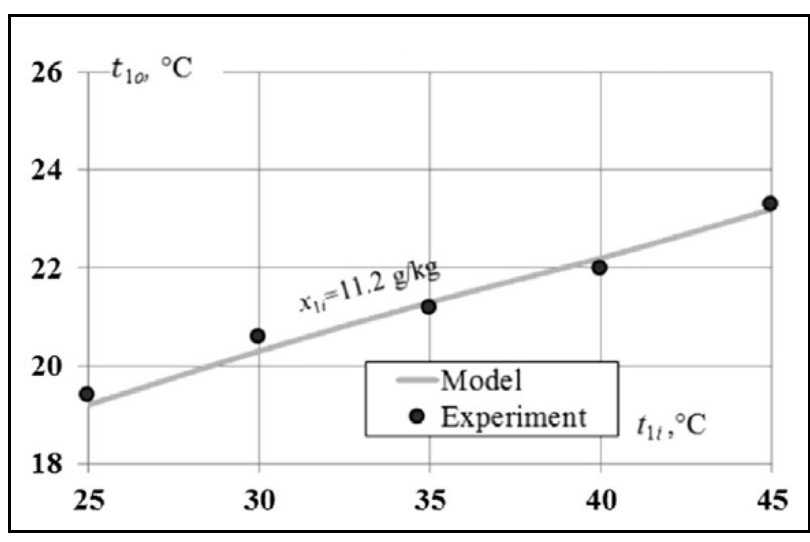

Fig. 5. Validation of the $\varepsilon$-NTU method results against experimental measurements data from [15] (a) Outlet product air temperature at variable velocity $v_{1}$ and constant inlet air parameters $\left(x_{1 i}=11.2 \mathrm{~g} / \mathrm{kg}\right)$ (b) Outlet product air temperature at variable inlet air temperature t1i and constant velocity $v_{1}\left(x_{1 i}=11.2 \mathrm{~g} / \mathrm{kg}\right)$.

\section{Desiccant wheel}

The $\varepsilon$-NTU model, which describes the desiccant wheel was validated according to experimental data given by Kowalski [16]. The experiment took place at the testing bench at Wroclaw University of Technology, Wroclaw, Poland. The wheel material consists of a mixture of a typical silica-gel (82\%) with unusual sorption isotherm shape [16] and a fiberglass. Kowalski used Biot criterion to ensure that the gradients in the perpendicular direction in the desiccant material can be omitted [16]. The selected graphs of model validation is presented in Fig. 6 (a) and (b). The discrepancies between the experimental and simulation results are at most $0.4 \mathrm{~g} / \mathrm{kg}$, the correlation coefficient R2 is equal 0.971 . It can be seen that the model and the experimental results show satisfactory agreement and trend, therefore the model can be used for numerical analysis of the desiccant wheel [9]. 
(a)

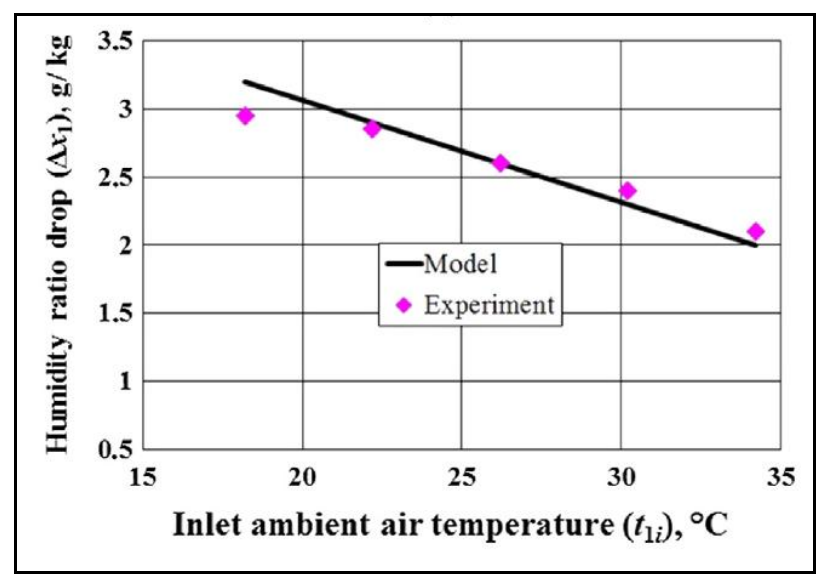

(b)

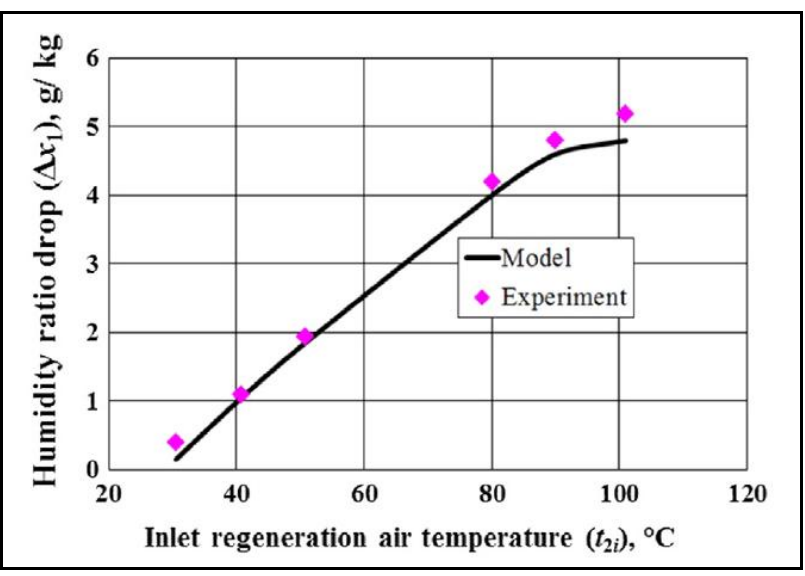

Fig. 6. Validation of mathematical model describing the desiccant wheel against data given by Kowalski [16]. (a) Ambient air humidity ratio drop at variable inlet ambient air temperature. (b) Ambient air humidity ratio drop at variable inlet regeneration air temperature.

\section{Analysis}

The mathematical models allow to analyze the system performance under different conditions. In this section a short analysis is presented to show the main advantages of System 1 over System 2 The obtained thermal COP indicator for both systems is presented. Moreover, analysis in next section is focused on comparison of System 1 and 2 in terms of ability to obtain similar dehumidification level. Due to this fact, the comparison is presented for different regeneration air temperatures for each system, which allow them to obtain similar dehumidification rate.

\subsection{Thermal COP indicator}

Ventilation systems with desiccant wheels need energy for regeneration to achieve a required cooling capacity. Heat for regeneration purposes may be partly obtained from thermal solar panels in typical moderate climate conditions. To check if System 1 is energy profitable, the coefficient of cooling performance indicator (COP) is analyzed in this section. COP is defined as a ratio, between the obtained system cooling capacity to energy required for regeneration:

$$
\mathrm{COP}=\frac{\Phi}{P}
$$

Obtained cooling capacity, $\mathrm{kW}$

$$
\Phi=V_{1 o}^{H M X 2} \rho\left(i_{E}-i_{1 o}^{H M X 2}\right)
$$

Required energy for regeneration purposes:

$$
P=V_{4} \rho c_{p}\left(t_{r e g}-t_{E}\right)
$$

Calculations of required energy for regeneration are executed with an assumption that ambient airflow is heated in order to achieve the regeneration airflow parameters. Cooling capacity is calculated with an assumption that the ambient air is cooled to the supply airflow parameters by each system. It can be seen that System 1 is characterized by visibly higher COP values comparing to System 2 (Fig. 7(a)). It is due to the fact that System 1 is able to produce more cooling capacity than System 2, with the same amount of regeneration energy needed. This is obtained due to the additional heat exchanger implementation which pre-cools the inlet airflow before the rotor dehumidifier. What is more, the higher inlet ambient airflow temperature the visible COP increment is observed because less energy is necessary to heat the air from higher temperatures to the required regeneration temperatures. Increasing the inlet ambient airflow humidity results in decreasing COP value (Fig. 7(b)). The highest COP obtained by System 1 equals 4.2 and it is almost two times higher comparing to System 2 for corresponding conditions (Fig 7(b)). Nevertheless, COP values for each system are still higher than 1.0 (more cooling capacity is obtained than energy for regeneration is utilized). It should be noted that System 1 COP values range between 1.4 and 4.2 for different ambient airflow parameters (see Figs. 7(a) and (b)).

(a)

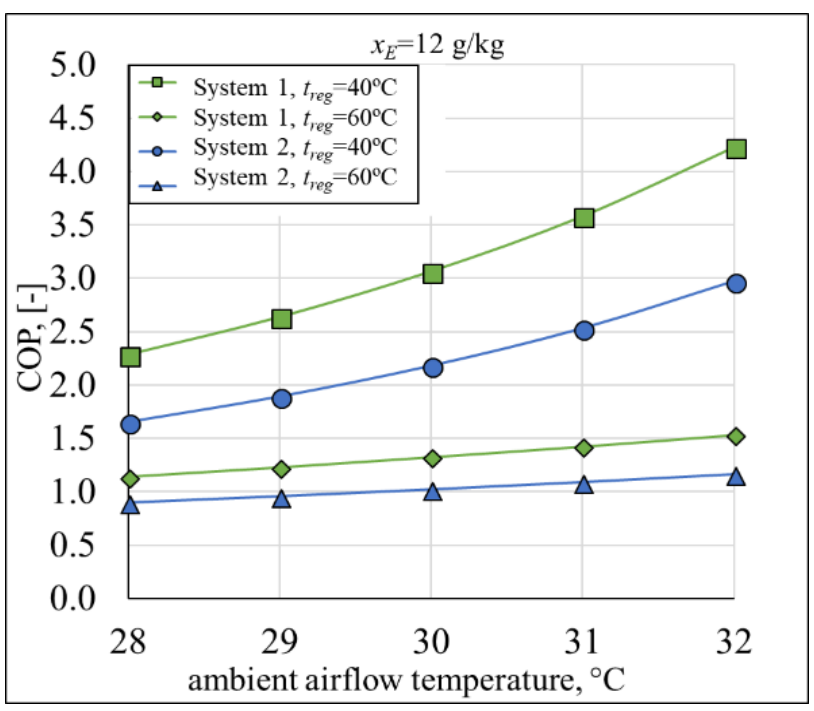


(b)

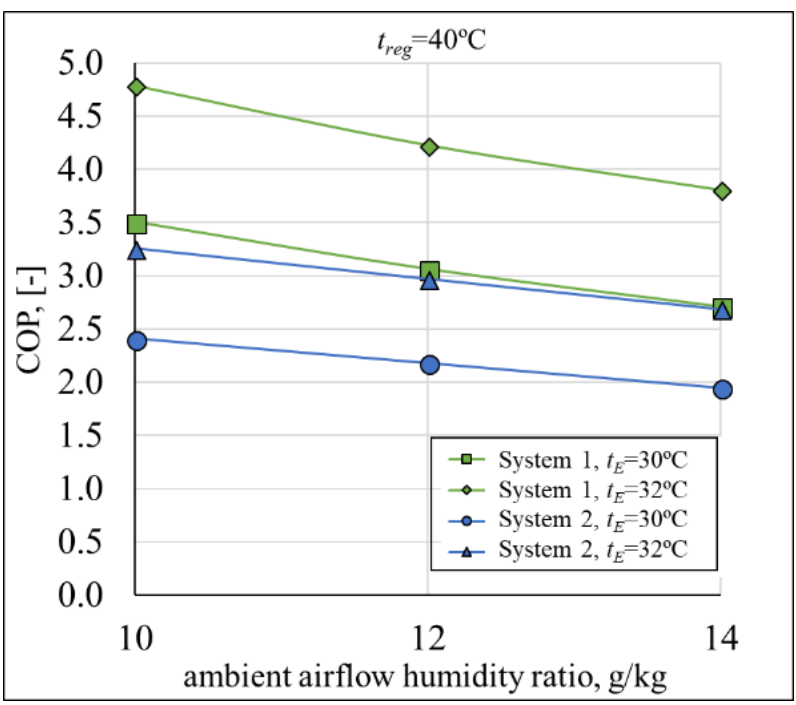

(c)

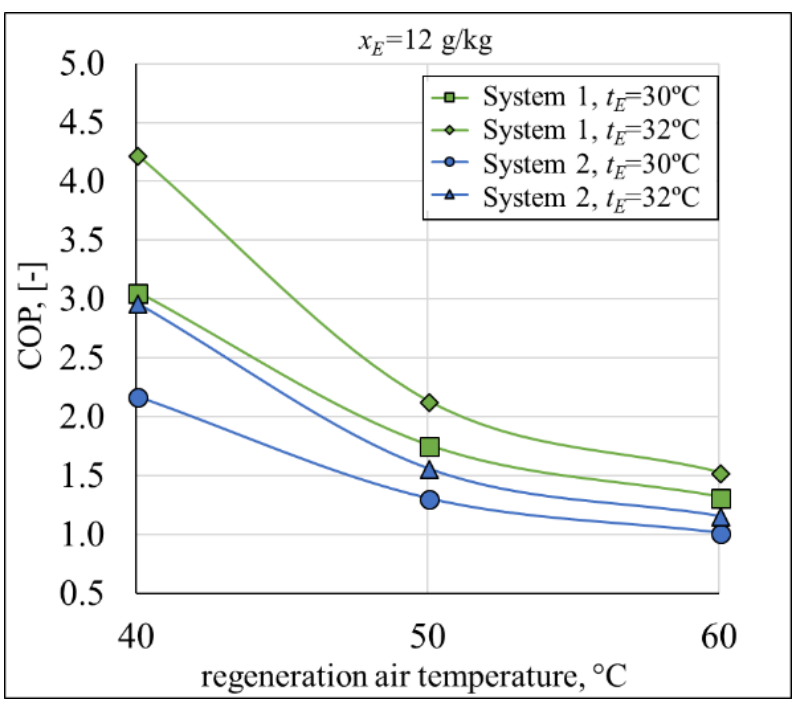

Fig. 7. Coefficient of performance (a) For the ambient airflow humidity ratio $x_{E}=12 \mathrm{~g} / \mathrm{kg}$ and different ambient airflow temperature. (b) For different ambient airflow humidity ratio. (c) For different regeneration airflow temperature.

The trends presented in Fig. 7(c) prove that increment of regeneration airflow temperature results in visible COP factor reduction. It can be concluded that for such systems heating the regeneration airflow to high temperatures becomes less favorable on the basis of COP factor. It is caused by the fact that increased regeneration temperature results in relative low increment of the produced cooling capacity.

\subsection{Obtained humidity ratio drop}

The data in Fig. 8 has been collated to present the diversity in the obtained supply airflow parameters by System 1 and 2 for different values of regeneration temperatures. It may be noted that to ensure the humidity ratio drop on the level of $2.75 \mathrm{~g} / \mathrm{kg}$ by System 2 , the required regeneration temperature is equal to $60^{\circ} \mathrm{C}$ (Fig. 8(b) point $\left.A^{\prime}\right)$. However, higher regeneration air temperature also results in higher supply air temperature obtained by System 2 (Fig. 8 (a) point A'). In order to provide the same humidity ratio drop by System 1, required regeneration temperature is be equal to less than $50^{\circ} \mathrm{C}$ (Fig. 8(b) point A). Due to this fact, the supply temperature obtained by System 1 lower in compare to System 2 (Fig. 8(a) point A). To provide the humidity ratio drop equal to $2.0 \mathrm{~g} / \mathrm{kg}$ the ambient air can be heated to the temperature $t_{r e g}=40^{\circ} \mathrm{C}$ while in System 2 it has to be over $50^{\circ} \mathrm{C}$ (Fig. 8(a) point B and B'). This also results in higher supply air temperature obtained by System 2 (Fig. 8(b) points B and B').

(a)

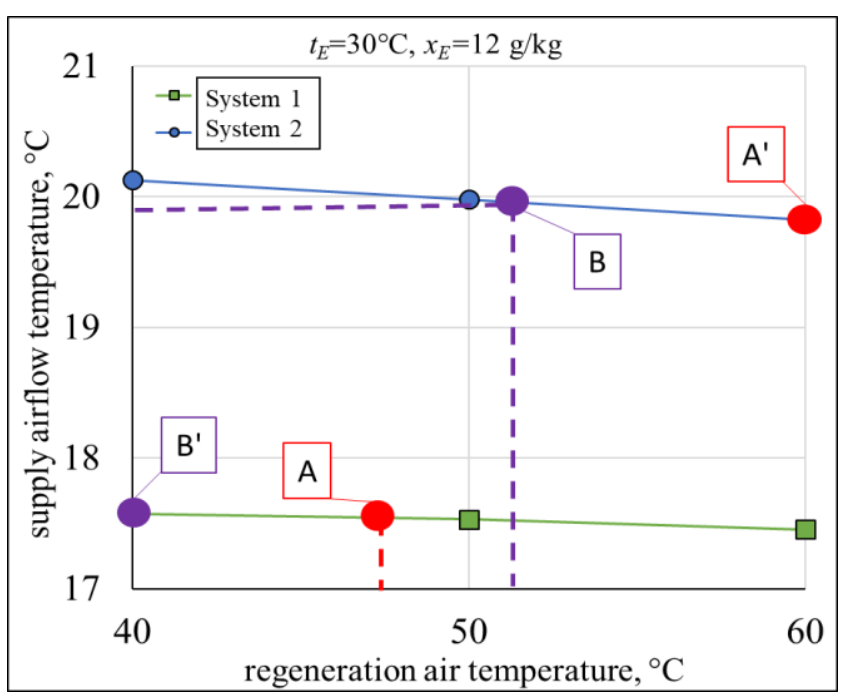

(b)

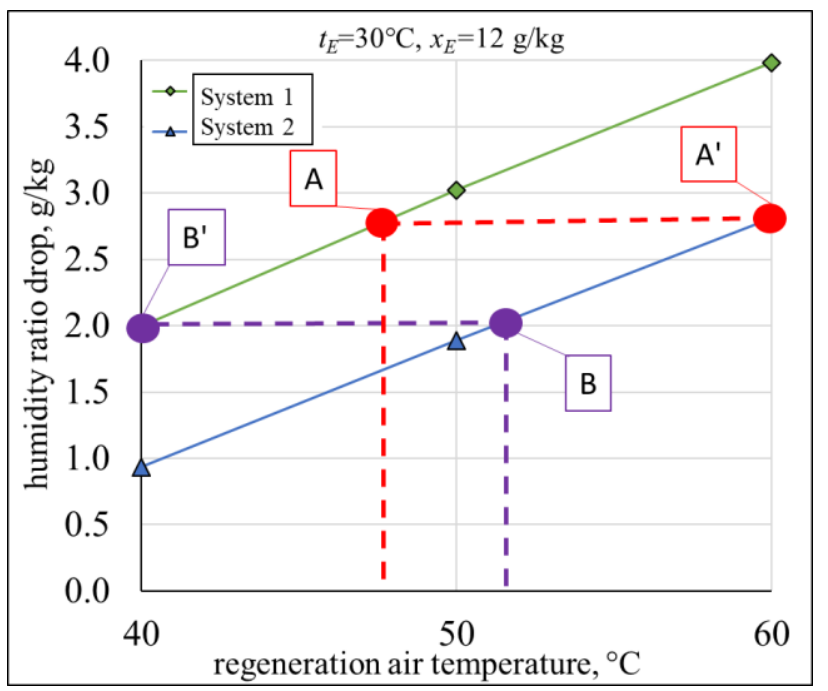

Fig. 8. Numerical simulation results. (a) Outlet temperatures of supply airflow under different regeneration temperatures (b) Humidity ratio drop of supply airflow under different regeneration temperatures.

\section{Conclusions}

The developed the original $\varepsilon$-NTU-model describing coupled heat and mass transfer in considered M-Cycle heat exchanger and desiccant wheel shows a satisfactory agreement with the experimental results. That is why 
$\varepsilon-\mathrm{NTU}$ method allows to analyze, develop and investigate the performance of ventilation systems successfully. In this study the basic comparison of two systems has been presented under moderate climate conditions. System 1 obtains higher thermal COP values, higher humidity ratio drop and lower supply airflow temperature (in comparison to System 2).

One of the co-authors, Demis Pandelidis, received financial support for his research from resources for scientific work for years 2016-2019 from Polish Ministry of Science and High Education (program "Iuventus Plus"), project number IP2015 058274 .

$A$ - Rotor desiccant sector area, $\mathrm{m}^{2}, c_{p}$ - specific heat capacity of moist air, $\mathrm{J} /(\mathrm{kg} \cdot \mathrm{K}) ; C$ - heat capacity rate of the fluid $\mathrm{W} / \mathrm{K}$ $\mathrm{COP}$ - thermal coefficient of performance, $-; F$ - surface area, $\mathrm{m}^{2} ; G-$ Moist air mass flow rate, $\mathrm{kg} / \mathrm{s} ; h$ - height, $\mathrm{m} ; i-$ specific enthalpy, $\mathrm{kJ} / \mathrm{kg} ; L, l-$ streamwise length of the cooler, $\mathrm{m}$;

$M$ - water vapor transfer rate, $\mathrm{kg} / \mathrm{s} ; \mathrm{P}$ - regeneration power,

$\mathrm{kW} ; \mathrm{R}$ - desiccant wheel radius, $\mathrm{m}$;

$t$ - temperature, ${ }^{\circ} \mathrm{C} ; V$ - volumetric airflow rate; $\mathrm{m}^{3} / \mathrm{h}$;

$q$ - specific heat, $\mathrm{kJ} / \mathrm{kg} ; Q$ - rate of heat transfer, $\mathrm{W}$;

$\mathrm{x}$ - humidity ratio, $\mathrm{g} / \mathrm{kg} ; X$ - coordinate along airflow direction, $\mathrm{m} ; Y$ - Heat exchanger width, $\mathrm{m} ; \mathrm{Z}_{3}$-coordinate along the process airflow direction: desiccant wheel, $\mathrm{m}$; $Z_{4}$ - coordinate along the regeneration airflow direction: desiccant wheel, $\mathrm{m} ; \tau$-Time, $\mathrm{m} ; \Delta \tau_{3}$-adsorption stage duration, $\mathrm{s} ; \Delta \tau_{4}-$ desorption stage duration, $\mathrm{s}$; $\Delta \tau_{0}$ - time of one revolution of the wheel,

$\Delta \tau_{0}=\Delta \tau_{3}+\Delta \tau_{4}, \mathrm{~s} ; \Phi-$ System cooling power, $\mathrm{kW}$;

$\Omega$ - Rotor desiccant rotation velocity, $1 / \mathrm{s}$;

$\alpha$-Convective heat transfer coefficient, $\mathrm{W} /\left(\mathrm{m}^{2} \mathrm{~K}\right)$;

$\beta$-mass transfer coefficient, $\mathrm{kg} /\left(\mathrm{m}^{2} \mathrm{~s}\right) ; \delta$ - thickness, $\mathrm{m}$;

$\sigma$-surface wettability factor, $\sigma \in(0.0$ to 1.0$)$; Le - Lewis factor $\mathrm{Le}=\alpha /\left(\beta c_{p}\right) ; \rho-$ air density, $\mathrm{kg} / \mathrm{m}^{3}$;

NTU - Number of transfer units

$\mathrm{NTU}=\alpha F /\left(G c_{p}\right) ; \mathrm{NTU}_{d}^{*}-$ Number of transfer units for the desiccant wheel $\mathrm{NTU}_{d}^{*}=\alpha F_{d} \Delta \tau_{o} /\left(M_{d} c_{d}\right)$;

$\bar{X}$ - relative $X$ coordinate $\bar{X}=X / l$;

$\bar{Z}-\bar{Z}=Z / L_{Z}$ relative $Z$ coordinate;

$\bar{\tau}$ - Non-dimensional time $\bar{\tau}=\tau / \tau_{0} ;$

$j$ - Wheel revolution counter $(j=(1 \ldots n))$

0 - initial condition, 1 - primary airflow; 2 - working airflow in the wet channels in product part of the exchanger; 3 process airflow in the process sector of the desiccant wheel; 4 - regeneration airflow in the regeneration sector of the desiccant wheel; cond - heat transfer by thermal conduction; $d$-desiccant material; $D H$ - desiccant wheel; $E$ - ambient air parameters;

$g$ - water vapor; HMX - heat and mass exchanger;

HMX1 - heat and mass exchanger no 1 ;

HMX2 - heat and mass exchanger no 2; $i$-inlet;

$o$ - outlet; $p$ - plate surface; $p l t$ - channel plate;

$L$ - latent heat flow; reg - referenced to regeneration airflow parameters; met - coating material (metal foil or polyethylene); $S$ - sensible; sorp - sorption;

- - referenced to the elementary plate surface;

\section{References}

1. International Energy Agency, The Future of Cooling - report (2018)

2. D. B. Jani, Manish Mishra, P.K. Sahoo, Renew. Sust. Energ. Rev. 60 (2016)

3. H. S. Dizaji, E. J. Hu, L. Chen, Energy 156 (2018)

4. A. Sohani, H. Sayyaadi and N. Mohammadhosseini, Energy. Convers. Manage. 158 (2018)

5. J. Nie, Z. Li, W. Hu, L. Fang, Q. Zhang, Energ. Buildings 153 (2017)

6. Y. Abbassi, E. Baniasadi, H. Ahmadikia, Energ. Buildings 150 (2017)

7. S. Anisimov, D. Pandelidis, J. Danielewicz, Energy Convers. Manage. 88 (2014)

8. S. Anisimov, D. Pandelidis, A. Jedlikowski, V. Polushkin, Energy 76 (2014)

9. D. Pandelidis, Mathematical modeling of the M-Cycle heat and mass exchanger used in air conditioning systems, PhD Dissertation, Supervisor: Professor Sergey Anisimov, Wrocław University of Technology, Department of Environmental Engineering (2015)

10. S. Anisimov, D. Pandelidis, Int. J. Heat Mass Tran. 84 (2015)

11. D. Pandelidis, S. Anisimov, W. M. Worek, P. Drąg, Energy Convers. Manage. 117 (2016)

12. V. Maisotsenko, L. Gillan and A. H. T. Gillan, Method and plate apparatus for dew point evaporative cooler (USA Patent US 7197887 B2, 2000)

13. S. Anisimov, D. Pandelidis, Int. J. Heat Mass Tran. 75 (2014)

14. S. Anisimov, D. Pandelidis, International Journal of Energy for a Clean Environment (Special Issue on M-Cycle Fundamentals and Applications) 12, Issue 2-4, 273-286, 2011

(DOI: 10.1615/InterJEnerCleanEnv.2012005770).

15. B. Riangvilaikul and S. Kumar, Energ. Buildings 42 (2010)

16. P. Kowalski, Heat and Mass Transfer in Rotary Dehumidifier for Solar Air Conditioning Systems, A Thesis Submitted to the Wroclaw University of Technology for the Degrees of Doctor of Philosophy (2007) 